\title{
Vanishing Bile Duct Syndrome and Hodgkin's Lymphoma: Case Report and Thorough Review of the Literature
}

\author{
Keramidas $\mathbf{V}^{1 \#}$, Tastanis $\mathbf{C}^{1 \#}$, Tsirogianni $\mathrm{K}^{1 \# \text {, }}$ \\ Hytiroglou $\mathrm{P}^{\mathbf{2}}$ and Papaioannou $\mathrm{M}^{\mathbf{1} *}$ \\ ${ }^{1}$ Hematology Unit, $1^{\text {st }}$ Department of Internal Medicine, \\ AHEPA University Hospital, Medical School, Aristotle \\ University of Thessaloniki, Greece \\ ${ }^{2}$ Department of Pathology, Medical School, Aristotle \\ University of Thessaloniki, Greece \\ \#Contributed Equally to this Work
}

*Corresponding author: Papaioannou M, Hematology Unit, 1 $^{\text {st }}$ Department of Internal Medicine, AHEPA University Hospital, Medical School, Aristotle University of Thessaloniki, S. Kiriakidi 1, 54636, Thessaloniki, Greece

Received: May 26, 2021; Accepted: J uly 13, 2021; Published: July 20, 2021

\begin{abstract}
Vanishing Bile Duct Syndrome (VBDS) is a rare, acquired disorder, characterized by progressive destruction and loss of intrahepatic bile ducts. The main clinical manifestations are jaundice and pruritus, caused by intralobular cholestasis. Although the pathogenic mechanism is poorly understood, VBDS has been associated with numerous etiologies such as medications, malignancies, infections and autoimmune diseases. This syndrome can appear as a paraneoplastic phenomenon in patients with Hodgkin's Lymphoma $(\mathrm{HL})$. Diagnosis is based on clinical evaluation and confirmed via liver biopsy, while treating the underlying cause is the main therapeutic target. If bile duct regeneration does not occur, possible outcomes include cirrhosis, hepatic failure and death, with liver transplantation being the only curative option.
\end{abstract}

In this paper, we describe a case of HL-related VBDS in a 31-year-old female patient, who presented with jaundice, pruritus and cervical lymphadenopathy. The stage of HL was determined as IIA and a liver biopsy was performed, which confirmed the degeneration of bile ducts. The patient was treated with the ABVD regimen and dexamethasone. Follow-up tests were normal and supported the full remission hypothesis. We conducted an analytical literature review and collected the available data from 38 confirmed cases, regarding the epidemiology, viral infections, clinical findings, therapeutic options and outcome.

Keywords: Vanishing bile duct syndrome; Hodgkin's lymphoma; Paraneoplastic cholestasis; Jaundice

\section{Introduction}

Vanishing Bile Duct Syndrome (VBDS) refers to a group of acquired disorders characterized primarily by cholestasis as a result of the progressive destruction and disappearance of the intrahepatic bile ducts. Although the pathogenetic mechanisms are not fully understood, VBDS has been associated with multiple etiologies including autoimmune diseases, infections, medications, neoplastic disorders and genetic abnormalities. VBDS can be a paraneoplastic manifestation of Hodgkin's Lymphoma (HL), which typically presents with jaundice, pruritus and weight loss. This paper aims to report a case of HL-related VBDS and review the existing literature.

\section{Case Presentation}

A 31-year-old woman was admitted to the hematology department with jaundice, pruritus and cervical lymphadenopathy of one month. Her past medical history is significant for heterozygous beta-thalassemia. Physical examination was repeated and confirmed the existence of jaundice and cervical lymphadenopathy. Her abnormal lab tests were: bilirubin $21.5 \mathrm{mg} / \mathrm{dl}$ [n.v. $<0.9 \mathrm{mg} / \mathrm{dl}$ ], direct $13.7 \mathrm{mg} / \mathrm{dl}[<0.3 \mathrm{mg} / \mathrm{dl}]$, LDH $1177 \mathrm{U} / \mathrm{L}[<240 \mathrm{U} / \mathrm{l}]$, SGOT $205 \mathrm{U} / \mathrm{L}$ [<32U/1], SGPT 258U/L [<33U/l], ALP 1041U/L [35-104 U/l], $\gamma$-GT $458 \mathrm{U} / \mathrm{L}$ [5-36 U/l], albumin $2.49 \mathrm{~g} / \mathrm{dl}[3.5-5.2 \mathrm{~g} / \mathrm{dl}]$, CRP $6.49 \mathrm{mg} / \mathrm{dl}$ $[<0.5 \mathrm{mg} / \mathrm{dl}]$, B2 microglobulin $5.28 \mathrm{mg} / \mathrm{L}[<2.5 \mathrm{mg} / \mathrm{L}]$. Blood counts revealed leukocytosis $(17.240 / \mu \mathrm{L})$, thrombocytosis $(701.000 / \mu \mathrm{L}), \mathrm{ESR}$
$140 \mathrm{~mm}$ and anemia (Hb 7.3g/dL). Viral hepatitis panel, HIV and Toxoplasma antibody tests were negative. However, EBV and CMV antibody tests were positive indicating a past infection. Remaining laboratory data including tumor markers and A1-antitrypsin were within normal limits.

Abdominal ultrasound examination did not reveal any pathological findings. The cervical lymphadenopathy required further investigation, so a biopsy was performed. HL (nodular sclerosis) was confirmed. A Computerized Tomography (CT) of the thorax and abdomen and a bone marrow biopsy was conducted to determine the stage of HL. Enlarged lymph nodes were detected at the mediastinum whereas the abdominal region was free of pathological findings and bone marrow biopsy was found to be normal. Keeping in mind that an abdominal CT scan is unable to detect intrahepatic filtration, a liver biopsy was performed (Figure 1). For that purpose, the levels of bilirubin needed to be reduced, so the patient was treated with dexamethasone $(40 \mathrm{mg} /$ day for 4 days). The+ liver biopsy revealed medium to severe centrilobular cholestasis, no neoplastic cells and degenerative alteration of bile ducts with more than $50 \%$ being absent in a specimen consisting of 10 portal triads. The stage of HL was IIA and VBDS was diagnosed. ABVD, the initial chemotherapy regimen for newly diagnosed early-stage HL, was administered to the patient, with half the dose of anthracycline for the first cycle and full dose thereafter.
Ann Hematol Oncol - Volume 8 Issue 9 - 2021

ISSN : 2375-7965 | www.austinpublishing group.com

Papaioannou et al. (C) All rights are reserved
Citation: Keramidas V, Tastanis C, Tsirogianni K, Hytiroglou P and Papaioannou M. Vanishing Bile Duct Syndrome and Hodgkin's Lymphoma: Case Report and Thorough Review of the Literature. Ann Hematol Oncol. 2021; 8(9): 1365. 

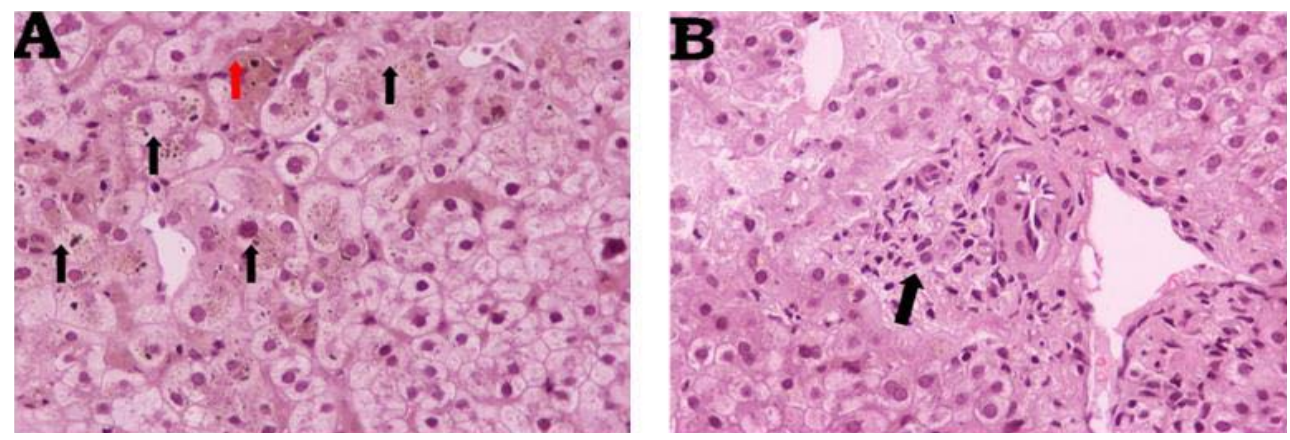

Figure 1: Liver biopsy. A) Significant centrilobular cholestasis, hepatocytes with feathery degeneration and bile pigments in their cytoplasm (black arrows). Red arrow, histiocyte accumulation with bile pigments and a bile cylinder. B) Portal area with mild lymphocytic infiltration and degenerative alterations of the bile duct epithelium. Hematoxylin-Eosin stain; 1×200.

Table 1: Causes of Vanishing Bile Duct Syndrome.

\begin{tabular}{c|l|}
\hline Congenital & Alagille Sydrome, Cystic Fibrosis, Alpha-1 Antitrypsin Deficiency, Progressive Familial Intrahepatic Cholestasis. \\
\hline Acquired & \multicolumn{1}{c}{$\begin{array}{l}\text { Non-FDA approved weight loss supplements, Sertraline, Oxcarbazepine, Chlorpromazine, Temozolomide, Carbamazepine, Interferon } \\
\text { Levofloxacin, Ibuprofen, Sulfamethoxazole-Trimethoprim, Meropenom, Lamotrigine, Valproic Acid, Azithromycin, Moxifloxacin, Mycophenolate } \\
\text { Mofetil, Anabolic Steroids, Allopurinol, Ciprofloxacin, Amoxicillin. }\end{array}$} \\
\hline Infections & $\mathrm{CMV}, \mathrm{HCV}, \mathrm{HBV}, \mathrm{EBV}$, Cryptosporidium, Reovirus type 3. \\
\hline Malignancy & Lymphoma (Hodgkin's, non- Hodgkin's), Histiocytosis X. \\
\hline Immunologic & Primary Biliary Cholangitis, Primary Sclerosing Cholangitis, Sarcoidosis, GvHD, Hepatic Allograft Rejection. \\
\hline
\end{tabular}

Not a comprehensive list.

After 6 cycles of treatment, her clinical and biochemical, profile was dramatically improved, while blood and liver function tests were within normal levels. A PET-CT scan was conducted, confirming the complete metabolic remission of HL. Two months later, a follow-up laboratory test revealed elevated levels of hepatic enzymes (SGOT 85U/L, SGPT 201U/L, ALP 250U/L, $\gamma$-GT 317U/L). For this reason, ursodeoxycholic acid was administered for 6 months, and liver biochemistry returned to normal. Although the regeneration of bile ducts was never confirmed via, liver biopsy, due to the patient's disapproval, recent laboratory tests showed normal levels of hepatic enzymes and consequently normal liver function to this day.

\section{Discussion}

A wide variety of conditions may lead to jaundice in HL since it is considered to be a relatively common manifestation among patients with HL. These conditions include biliary obstruction secondary to lymph node enlargement, biliary and hepatic infiltration, hemolysis, viral illnesses (most commonly CMV and hepatitis), drug toxicity, Idiopathic Cholestasis (IC) and VBDS [1].

VBDS is an uncommon condition characterized by ductopenia, which results in cholestasis and eventually in secondary biliary cirrhosis and liver failure. Apart from HL, VBDS has been associated with numerous other etiologies, congenital or acquired (Table 1).

Bouroncle had noticed the phenomenon of HL-related IC in two patients with known HL, but without lymphomatous involvement of the liver or any other cause for liver dysfunction [2]. Until 1993, when Hubscher first used the term "vanishing bile duct syndrome" and described the association between VBDS and HL [3], all cases were attributed to IC and other similar diagnoses. A literature review was conducted, and Supplementary Table 1 presents all published cases
Table 2: Summary of clinical features of patients with VBDS related to Hodgkin's lymphoma.

\begin{tabular}{|c|c|}
\hline Jaundice & $38 / 38(100 \%)$ \\
\hline Pruritus & $18 / 18(100 \%)$ \\
\hline Weight loss & $21 / 22(95.45 \%)$ \\
\hline Night Sweats & $12 / 16(71.43 \%)$ \\
\hline Fever & $15 / 19(78.95 \%)$ \\
\hline Lymphadenopathy & $33 / 34(97.06 \%)$ \\
\hline Hepatomegaly & $11 / 25(44 \%)$ \\
\hline Splenomegaly & $10 / 27(37.04 \%)$ \\
\hline
\end{tabular}

of HL-related VBDS, until recently, including those, which were not confirmed as VBDS via liver biopsy even though there is significant evidence that, can prove so.

We collected the data from 38 confirmed VBDS related to HL cases. The mean age of patients is 32 years (range 3.5-75 years) with a male predominance $(2: 1)$. All patients presented with jaundice, while other common manifestations were pruritus and weight loss. Night sweats and fever appeared in many cases. In nearly half of the patients, clinical examination revealed hepatomegaly and in $37 \%$ splenomegaly (Table 2). It is interesting that while almost all patients had lymphadenopathy due to HL, in four cases the diagnosis of VBDS preceded the diagnosis of $\mathrm{HL}$, because the pathological lymph nodes were not noted initially [4-7]. As a result, VBDS was attributed to other causes, until HL could be identified. There is one case in which lymphadenopathy was absent since VBDS appeared six months after the full remission of HL [8].

The stage of HL was reported in 29 cases. The majority of them were distributed in stages III and II, 14 and 12 respectively. 
Approximately $25 \%$ of all patients had previous or active infections from viruses that affect the liver (EBV, CMV, hepatotropic viruses). Both total and direct bilirubin levels (as measured on admission in all patients) were elevated with a mean value of $17.35 \mathrm{mg} / \mathrm{dL}(\mathrm{n}=35)$ and $10.86 \mathrm{mg} / \mathrm{dL}(\mathrm{n}=19)$. It was observed that in cases, in which full remission was achieved, the mean value of total bilirubin was 15.1 $\mathrm{mg} / \mathrm{dL}$, while the respective value in deceased patients was $20.01 \mathrm{mg} /$ dL. The vast majority of all cases (27/39) were treated with various chemotherapy regimens (with or without corticosteroids and/or UDCA). In this group, the remission rate was up to $48 \%$. Ten patients received chemotherapy combined with radiotherapy, with a similar remission rate $(5 / 10)$. Overall remission rate was calculated as $43.6 \%$ (17/39), while two patients were awaiting further treatment, at the time of publication $[9,10]$. The predominant cause of death was hepatic failure $(52.6 \%)$, followed by sepsis $(26.3 \%)$.

The etiologic relationship between VBDS and HL is poorly understood, although it seems that two pathogenic mechanisms exist. The first mechanism (direct) involves hepatic infiltration by lymphoma cells, leading to bile duct destruction. Hubscher [3] continued by suggesting a different, indirect mechanism, which can be described as a paraneoplastic phenomenon. According to the latter, toxic cytokines released from HL cells, induce a cellmediated destruction. There is evidence that biliary epithelial cells express Major Histocompatibility Complex (MHC), antigens (both class I and II) and adhesion molecules, which respond to cytokines produced by HL. T-lymphocytes adhere to this complex $[1,11]$ and attack the bile ducts, resulting in their disappearance [12]. Noticeably, most of the reported cases specify that a liver biopsy was performed prior to treatment, which leads to the conclusion that the second mechanism may prevail [13]. Hubscher was unable to exclude the lymphomatous hepatic infiltration as the leading cause of VBDS, since he had administered chemotherapy before the liver biopsies [3]. According to recent investigations, immunoglobulins are found in interlobular bile ducts in some cases, suggesting that a humoral immune reaction may be happening as well $[11,10]$.

The diagnosis of VBDS can be challenging. Laboratory findings include nonspecific elevations of alkaline phosphatase, $\gamma$-glutamyl transpeptidase, alanine aminotransferase and bilirubin levels, all of which compose a clinical profile, characterized by jaundice and pruritus [13]. Ultrasound, CT-scanning and MRI do not contribute significantly to the diagnostic procedure. In order to confirm the diagnosis, it is necessary that subsequent liver biopsies reveal intrahepatic cholestasis and severe bile duct destruction. In particular, it is defined by the loss of more than $50 \%$ of interlobular bile ducts in a pathologic specimen that includes at least 10 portal triads [14]. Along with the histological evidence, it is important that all other causes for cholestasis are excluded, such as large duct disease, EBV and CMV infections, viral hepatitis, mechanical obstruction, primary biliary cirrhosis and primary sclerosing cholangitis [1].

Treating the underlying cause is considered the main objective. It is crucial that therapy is initiated prior to the histological confirmation of VBDS, due to the fact that a delayed start may be proven detrimental to the outcome. Patients with HL are traditionally treated with the ABVD (Adriamycin, Bleomycin, Vinblastine, Dacarbazine) regimen and targeted radiotherapy [14]. Supportive care includes ursodeoxycholic acid (UDCA) and immunosuppressants, such as corticosteroids. UDCA is a secondary bile acid. Experimental evidence suggests that UDCA not only stimulates hepatobiliary secretion but also protects cholangiocytes and hepatocytes against apoptosis and toxicity [15]. Thus, UDCA was administered to 9 out of 39 patients, including our own patient (Supplementary Table 1), in order to improve liver function and allow a liver biopsy or chemotherapy to be conducted. Corticosteroids have also been used successfully for the aforementioned reasons, due to their proven anti-inflammatory effect $[16,17]$.

Conventional drug combinations and effective chemotherapeutic doses are often difficult to be administered to patients with HL-related VBDS, since their liver function is severely affected. Treatment for those patients must balance between chemoradiation and the need to preserve liver function. The current treatment strategy revolves around chemotherapy regimens, which are safe for the liver [7]. Once liver function improves, standard regimens can be administered [18]. Nevertheless, the available literature includes cases in which full doses of chemotherapy were used, leading to a plethora of outcomes, including remission [1,11]. Rota Scalabrini et al. [1] proposed that in order to achieve complete remission, an aggressive approach is necessary, consisting of full dose high-intensity chemotherapy. It is essential that patients, whose liver function is severely affected, are taken into consideration for liver transplantation. However, some authors suggest that all cases of HL-related VBDS should be treated as potential candidates for transplantation $[2,3,11,12,19]$.

Given the presumed immunological reaction causing VBDS, treatments targeting this response have also been attempted. Keeping in mind that a humoral immune reaction may be the cause of VBDS, Hallen proposed the use of Rituximab, a chimeric monoclonal antiCD20-antibody used against CD20-positive B-cell lymphomas. The subtype of HL that can be treated with Rituximab is the nonclassical nodular lymphocyte predominant, in which the tumor cells are CD20- positive. Although Rituximab is traditionally used for the treatment of this unusual subtype, it has been reported that it may be effective against other types of HL as well $[11,20]$. Rituximab has also been used in two other known cases [9,7].

\section{Conclusion}

Vanishing bile duct syndrome is considered a rare condition; thus, it can easily elude the attention of health care professionals. Laboratory findings are not pathognomonic and the imaging examinations do not contribute to the diagnostic procedure. Therefore, raising the index of suspicion is the key to diagnosis. It is crucial that practitioners are aware of the association between HL and VBDS and the fact that the manifestations of VBDS may precede the diagnosis of HL.

\section{References}

1. Rota Scalabrini D, Caravelli D, Carnevale Schianca F, D'Ambrosio L, Tolomeo $\mathrm{F}$, Boccone $\mathrm{P}$, et al. Complete remission of paraneoplastic vanishing bile duct syndrome after the successful treatment of Hodgkin's lymphoma: a case report and review of the literature. BMC Res Notes. 2014; 7: 529.

2. Bouroncle BA, Old JW Jr, Vazques AG. Pathogenesis of jaundice in Hodgkin's disease. Arch Intern Med. 1962; 110: 872-883.

3. Hubscher SG, Lumley MA, Elias E. Vanishing bile duct syndrome: a possible mechanism for intrahepatic cholestasis in Hodgkin's lymphoma. Hepatology. 1993; 17: 70-77. 
4. Ballonoff A, Kavanagh B, Nash R, Drabkin H, Trotter J, Costa L, et al. Hodgkin lymphoma-related vanishing bile duct syndrome and idiopathic cholestasis: statistical analysis of all published cases and literature review. Acta Oncol. 2008; 47: 962-970

5. DeBenedet AT, Berg CL, Enfield KB, Woodford RL, Bennett AK, Northup PG. A case of vanishing bile duct syndrome and IBD secondary to Hodgkin's lymphoma. Nat Clin Pract Gastroenterol Hepatol. 2008; 5: 49-53.

6. Das A, Mitra S, Ghosh D, Modi SK, Roy P, Das J, et al. Vanishing Bile Duct Syndrome following cytomegalovirus infection in a child with Hodgkin lymphoma. J Pediatr Hematol Oncol. 2018; 40: 83-84.

7. Anugwom C, Goetz G, Hassan M. Vanishing Bile Duct Syndrome preceding the diagnosis of Hodgkin lymphoma. ACG Case Rep J. 2020; 7: e00336.

8. Amer S, Muqeetadnan M, Rahman A, Nusrat S, Hassan S. Vanishing bile duct syndrome: a rare cause of jaundice in Hodgkin's lymphoma. Turk J Gastroenterol. 2013; 24: 444-446.

9. Pass AK, McLin VA, Rushton JR, Kearney DL, Hastings CA, Margolin JF. Vanishing bile duct syndrome and Hodgkin disease: a case series and review of the literature. J Pediatr Hematol Oncol. 2008; 30: 976-980.

10. Greca RD, Cunha-Silva M, Costa LBE, Costa JGF, Mazo DFC, Sevá-Pereira $\mathrm{T}$, et al. Vanishing bile duct syndrome related to DILI and Hodgkin lymphoma overlap: A rare and severe case. Ann Hepatol. 2020; 19: 107-112.

11. Bakhit M, McCarty TR, Park S, Njei B, Cho M, Karagozian R, et al. Vanishing bile duct syndrome in Hodgkin's lymphoma: A case report and literature review. World J Gastroenterol. 2017; 23: 366-372.

12. Rossini MS, Lorand-Metze I, Oliveira GB, Souza CA. Vanishing bile duct syndrome in Hodgkin's disease: case report. Sao Paulo Med J. 2000; 118: 154-157.

13. Wong KM, Chang CS, Wu CC, Yin HL. Hodgkin's lymphoma-related vanishing bile duct syndrome: a case report and literature review. Kaohsiung J Med Sci. 2013; 29: 636-641.

14. LiverTox: Clinical and Research Information on Drug-Induced Liver Injury [Internet]. Bethesda (MD): National Institute of Diabetes and Digestive and Kidney Diseases. 2012

15. PusI T, Beuers U. Ursodeoxycholic acid treatment of vanishing bile duct syndromes. World J Gastroenterol. 2006; 12: 3487-3495.

16. Paumgartner G, Beuers U. Ursodeoxycholic acid in cholestatic liver disease: mechanisms of action and therapeutic use revisited. Hepatology. 2002; 36: 525-531.

17. Piawah S, Hyland C, Umetsu SE, Esserman LJ, Rugo HS, Chien AJ. A case report of vanishing bile duct syndrome after exposure to pexidartinib (PLX3397) and paclitaxel. NPJ Breast Cancer. 2019; 5: 17.

18. Sathyanarayanan V, Foo WC, Fanale M, Westin J. Deeper insights into Vanishing Bile Duct Syndrome in Lymphoma: A perplexing entity. Clin Lymphoma Myeloma Leuk. 2016; 16: e65-70.

19. Gottrand F, Cullu F, Mazingue F, Nelken B, Lecomte-Houcke M, Farriaux JP. Intrahepatic cholestasis related to vanishing bile duct syndrome in Hodgkin's disease. J Pediatr Gastroenterol Nutr. 1997; 24: 430-433.

20. Hallén K, Sangfelt P, Nilsson T, Nordgren H, Wanders A, Molin D. Vanishing bile duct-like syndrome in a patient with Hodgkin lymphoma - pathological development and restitution. Acta Oncol. 2014; 53: 1271-1275.

21. Fong M, Boyle S, Gutta N. Brentuximab vedotin in combination with sequentia procarbazine, cyclophosphamide and prednisolone for the management of Hodgkin's lymphoma-associated vanishing bile duct syndrome (VBDS) with severe obstructive liver failure. BMJ Case Rep. 2019; 12: e227676.

22. Das A, Mitra S, Ghosh D, Modi SK, Roy P, Das J, et al. Vanishing Bile Duct Syndrome following cytomegalovirus infection in a child with Hodgkin lymphoma. J Pediatr Hematol Oncol. 2018; 40: 83-84.

23. Bakhit M, McCarty TR, Park S, Njei B, Cho M, Karagozian R, et al. Vanishing Bile Duct Syndrome in Hodgkin's lymphoma: A single center experience and clinical pearls. J Clin Gastroenterol. 2016; 50: 688.

24. Yeh P, Lokan J, Anantharajah A, Grigg A. Vanishing bile duct syndrome and immunodeficiency preceding the diagnosis of Hodgkin lymphoma. Intern Med J. 2014; 44: 1240-1244

25. Nader K, Mok S, Kalra A, Harb A, Schwarting R, Ferber A. Vanishing bile duct syndrome as a manifestation of Hodgkin's lymphoma: a case report and review of the literature. Tumori. 2013; 99: e164-168.

26. Aleem A, Al-Katari M, Alsaleh K, AlSwat K, Al-Sheikh A. Vanishing bile duct syndrome in a Hodgkin's lymphoma patient with fatal outcome despite lymphoma remission. Saudi J Gastroenterol. 2013; 19: 286-289.

27. Umit H, Unsal G, Tezel A, Soylu AR, Pamuk GE, Turgut B, et al. Vanishing bile duct syndrome in a patient with Hodgkin's lymphoma and asymptomatic hepatitis B virus infection. Acta Gastroenterol Belg. 2009; 72: 277-278.

28. Leeuwenburgh I, Lugtenburg EP, van Buuren HR, Zondervan PE, de Man RA. Severe jaundice, due to vanishing bile duct syndrome, as presenting symptom of Hodgkin's lymphoma, fully reversible after chemotherapy. Eur J Gastroenterol Hepatol. 2008; 20: 145-147.

29. Schmitt A, Gilden DJ, Saint S, Moseley RH. Clinical problem solving. Empirically incorrect. N Engl J Med. 2006; 354: 509-514.

30. Han WS, Jung ES, Kim YH, Kim CH, Park SC, Lee JY, et al. [Spontaneous resolution of vanishing bile duct syndrome in Hodgkin's lymphoma]. Korean J Hepatol. 2005; 11: 164-168.

31. Córdoba Iturriagagoitia $A$, Iñarrairaegui Bastarrica $M$, Pérez de Equiza $E$, Zozaya Urmeneta JM, Martínez-Peñuela JM, Beloqui Pérez R. Recuperación ductular en el síndrome de los conductillos biliares evanescent en paciente con linfoma de Hodgkin [Ductal regeneration in vanishing bile duct syndrome in Hodgkin's lymphoma]. Gastroenterol Hepatol. 2005; 28: 275-278.

32. Guliter S, Erdem O, Isik M, Yamac K, Uluoglu O. Cholestatic liver disease with ductopenia (vanishing bile duct syndrome) in Hodgkin's disease: report of a case. Tumori. 2004; 90: 517-520.

33. Kömürcü S, Ozet A, Altundag MK, Arpaci F, Oztürk B, Celasun B, et al. Vanishing bile duct syndrome occurring after high-dose chemotherapy and autologous peripheral stem cell transplantation in a patient with Hodgkin's disease. Ann Hematol. 2002; 81: 57-58.

34. Ripoll C, Carretero L, Sabin P, Alvarez E, Marrupe D, Bañares R. Colestasis idiopática asociada a ductopenia progresiva en dos pacientes con linfoma de Hodgkin [Idiopathic cholestasis associated with progressive ductopenia in two patients with hodgkin's disease]. Gastroenterol Hepatol. 2002; 25: 313315.

35. Ozkan A, Yoruk A, Celkan T, Apak H, Yildiz I, Ozbay G. The vanishing bile duct syndrome in a child with Hodgkin disease. Med Pediatr Oncol. 2001; 36: 398-399.

36. Allory Y, Métreau J, Zafrani E. Raréfaction paranéoplasique des canaux biliaires interlobulaires au cours d'un cas de maladie de Hodgkin [Paraneoplastic vanishing bile duct syndrome in a case of Hodgkin's disease]. Ann Pathol. 2000; 20: 52-55.

37. Yusuf MA, Elias E, Hübscher SG. Jaundice caused by the vanishing bile duct syndrome in a child with Hodgkin lymphoma. J Pediatr Hematol Oncol. 2000; 22: 154-157.

38. de Medeiros BC, Lacerda MA, Telles JE, da Silva JA, de Medeiros CR. Cholestasis secondary to Hodgkin's disease: report of 2 cases of vanishing bile duct syndrome. Haematologica. 1998; 83: 1038-1040.

39. Crosbie OM, Crown JP, Nolan NP, Murray R, Hegarty JE. Resolution of paraneoplastic bile duct paucity following successful treatment of Hodgkin's disease. Hepatology. 1997; 26: 5-8.

40. Barta SK, Yahalom J, Shia J, Hamlin PA. Idiopathic cholestasis as a paraneoplastic phenomenon in Hodgkin's lymphoma. Clin Lymphoma Myeloma. 2006; 7: 77-82.

41. Liangpunsakul S, Kwo P, Koukoulis GK. Hodgkin's disease presenting as cholestatic hepatitis with prominent ductal injury. Eur J Gastroenterol Hepatol. 2002; 14: 323-327.

42. Dourakis SP, Tzemanakis E, Deutsch M, Kafiri G, Hadziyannis SJ. Fulminant hepatic failure as a presenting paraneoplastic manifestation of Hodgkin's disease. Eur J Gastroenterol Hepatol. 1999; 11: 1055-1058. 
43. Yalçin S, Kars A, Sökmensüer C, Atahan L. Extrahepatic Hodgkin's disease with intrahepatic cholestasis: report of two cases. Oncology. 1999; 57: 83-85.

44. Warner AS, Whitcomb FF. Extrahepatic Hodgkin's disease and cholestasis. Am J Gastroenterol. 1994; 89: 940-941.

45. Jansen PL, van der Lelie $H$. Intrahepatic cholestasis and biliary cirrhosis associated with extrahepatic Hodgkin's disease. Neth J Med. 1994; 44: 99 102

46. Birrer MJ, Young RC. Differential diagnosis of jaundice in lymphoma patients Semin Liver Dis. 1987; 7: 269-277.

47. Lieberman DA. Intrahepatic cholestasis due to Hodgkin's disease. An elusive diagnosis. J Clin Gastroenterol. 1986; 8: 304-307.

48. Trewby PN, Portmann B, Brinkley DM, Williams R. Liver disease as presenting manifestation of Hodgkin's disease. Q J Med. 1979; 48: 137-150.
49. Piken EP, Abraham GE, Hepner GW. Investigation of a patient with Hodgkin's disease and cholestasis. Gastroenterology. 1979; 77: 145-147.

50. Perera DR, Greene ML, Fenster LF. Cholestasis associated with extrabiliary Hodgkin's disease. Report of three cases and review of four others. Gastroenterology. 1974; 67: 680-685.

51. Groth CG, Hellström K, Hofvendahl S, Nordenstam H, Wengle B. Diagnosis of malignant lymphoma at laparotomy disclosing intrahepatic cholestasis. Acta Chir Scand. 1972; 138: 186-189.

52. Juniper K Jr. Prolonged severe obstructive jaundice in Hodgkin's disease Gastroenterology. 1963; 44: 199-204. 